\title{
Nutritional Status and Hygiene Behavior of Government Primary School Kids in Central Bangladesh
}

\author{
Md. Abdul Hakim ${ }^{1, ~ *, ~ M d . ~ J a l a l ~ T a l u k d e r ~}{ }^{1}$, Md. Serajul Islam² \\ ${ }^{1}$ Department of Food Technology and Nutritional Science, Faculty of Life Science, Mawlana Bhashani Science and Technology University, \\ Santosh, Tangail, Bangladesh \\ ${ }^{2}$ Society for Social Service (SSS), SSS Bhaban, Tangail, Bangladesh
}

Email address:

info.hakim.bd@gmail.com (M. A. Hakim), jalal.info10mission@gmail.com (M. J. Talukder), serajftns@gmail.com (M. S. Islam)

\section{To cite this article:}

Md. Abdul Hakim, Md. Jalal Talukder, Md. Serajul Islam. Nutritional Status and Hygiene Behavior of Government Primary School Kids in Central Bangladesh. Science Journal of Public Health. Vol. 3, No. 5, 2015, pp. 638-642. doi: 10.11648/j.sjph.20150305.17

\begin{abstract}
The study was conducted among kids at the campus of Town Government Primary School, Darul Ulum Government Primary School and Jahangir Smrity Seberasrom Government Primary School in Tangail municipality, the hub of the Tangail district and consequently the central body of Bangladesh. From these three schools $60 \%(n=45)$ boys and $40 \%(n=30)$ girls were selected for the study by using the simple random sampling method. Results reveal that $80 \%(\mathrm{n}=12), 73.33 \%(\mathrm{n}=11), 86.67 \%$ $(n=13), 80 \%(n=12)$ and $77.33 \%(n=11)$ school kids were in underweight at class 1 to class 5 orderly, 20\% $(n=3)$ kids were in normal weight at classes 1,2 and 4 and $13.33 \%(n=2)$ and $6.67 \%(n=1)$ kids in normal weight at classes 5 and $3.6 .67 \%(n=1)$ kids were overweight at classes 2,3 and 5 and $6.67 \%(n=1)$ was obese in class 5 . The basic hygiene behaviors of children have significant positive effects on their nutritional status. Almost $100 \%$ school kids told that they always washed their hands with shop before and after meal taking and after the use of toilet and $98.67 \%(n=74)$ washed their hand coming back home from outside. About 77.78\% $(n=35), 17.78 \%(n=8)$ and $4.44 \%(n=2)$ boys brushed their teeth two, one and three times a day respectively while $66.67 \%(\mathrm{n}=20), 20 \%(\mathrm{n}=6)$ and $13.33 \%(\mathrm{n}=4)$ girls brushed teeth two, one and three times a day respectively. The study also showed that $97.78 \%(n=44)$ boys and $93.33 \%(n=28)$ girls used sandal all the day as one of their main hygiene practices.
\end{abstract}

Keywords: Nutritional Status, Hygiene Behavior and Primary School Kids

\section{Background}

The Tangail municipality by the mighty Louhjang river of Tangail Sadar upazila at Tangail district is the central section in Bangladesh based on demographic settlement of sum 64 districts under the 7 division in Bangladesh. The Tangail district of some 3.6 million people is surrounded by Jamalpur district on the north, the Dhaka and Manikganj districts on the south, the Mymensingh and Gazipur districts on the east and the Sirajganj district on the west [1]. The shifting of remote villagers in Tangail municipality in search of proper education, housing, gas and power supply and better economic earning chance have turned the municipality a concentrated jungle. The impromptu houses and markets construction are liable for inadequate fields, open spaces, swimming pools, botanical gardens, zoological gardens and children's parks. As a result, the kids are suffering in malnutrition and malnutrition is on the helm of galore public panic in the district [2]. Malnourished kids are generally shorter and lighter in association with height-for-age and weight-for-age [3-6]. Malnutrition, especially the under nutrition is highly prevalent in order to combined effort of inadequate dietary intake [7], dare to elude basic hygienic practice and frequent infection regardless of adopting economic development in the developing countries [8-10]. There are different studies in different countries at different time frame to identify respiratory problems [9\&11], diarrhea [12], anaemia [13-16], parasitic infections, pediculous, refractive errors [17], skin diseases, caries teeth [18], vitamin A deficiency diseases and Xeropthalmia [19\&20], nematode infection [21], ear and throat problems [22], sleeping disorders, tic disorders [23] etc of primary school kids. Stunting and wasting are in vast spreading among school kids in developing countries [24-26]. High degree of stunting among kids suggest to have long term deficit in physical and mental improvement 
leading the maximum school absence and least learning opportunities [9]. Epidemiologic evidence showed strong bond between maternal and early childhood under nutrition and increased adult risk of different chronic diseases [27\&28]. A sum of $52 \%$ school going kids in under developed countries is normal, while $48 \%$ of them are malnourished and $10 \%$ of them are severely malnourished [5, 7\&29]. There are more than 200 million school kids are stunned and if action delayed, nearly 1 billion stunned school kids would be growing up by 2020 with impaired physical and mental well-being [30]. Bangladesh is also facing high proportion of pauperism and child malnutrition [9\&31]. The school going kids in Bangladesh-like developing countries are often the sufferers of communicable diseases [32\&33] which can hamper their school attendance and class performance also $[34,35]$. An abundance fraction of world's illness and death is attributable to communicable diseases [36\&37]. About $31 \%$ and $62 \%$ of all the deaths in South Asia and Africa are seen due to infectious diseases [38], while overweigh and obesity is identified as the biggest contributing factor to chronic illnesses in the developed world [39\&40]. The first and foremost aim of the study was to assess the nutritional status of the government primary school kids and their hygiene behavior in the central Bangladesh with a view to attain their safe childhood.

\section{Methodology}

\subsection{Study Nature}

The study was a cross-sectional study.

\subsection{Study Areas}

The premises of the Town Government Primary School, Darul Ulum Government Primary School and Jahangir Smrity Seberasrom Government Primary School of Tangail municipality at Tangail district in Bangladesh.

\subsection{Study Duration}

The study was conducted from January 2015 to May 2015.

\subsection{Study Population}

There were taken a total of 75 school kids sorting the boys and girls in the ratio of 3: 2 from each class of the selected primary schools at Tangail municipality in Tangail district.

\subsection{Sampling Method}

The simple random sampling method was adopted to sort the boys and girls inside the study population from each class of the selected primary schools.

\subsection{Data Aggregating Techniques}

A questionnaire was formed containing both the open and closed ended questions with a view to aggregate the relative query on hygiene behavior, anthropometric, social, economic and demographic assessment. The school kids, their guardians and teachers were the questionnaire answer providers.

\subsubsection{Anthropometric Data}

The anthropometric data were measured applying the following procedure:

\subsubsection{Body Weight Measurement}

The body weight was recorded in kilogram using standard weighing machine. The study participants were in bare footed with light cloths during weight taking period.

\subsubsection{Height Measurement}

Modified tape was used to record the height of the study respondents in miter. The participants were positioned to stand on a platform, bare footed with their head upright, looking straight forward at the time of taking height.

\subsubsection{Nutritional Status Assessment}

The nutritional status of the primary school kids was assessed using the Quetelet Index.

\subsubsection{Hygiene Behavior Assessment}

There were taken some hygiene linked query in the developed questionnaire like hand washing practice, brushing practice and sandal using all day.

\subsubsection{Data Verification and Analysis}

The data was first checked, cleaned and entered into the computer technology. The data was edited if there were any discrepancy sighted. The frequency distribution of the variables was checked by using SPSS 16 for windows program. The new variables gained were recorded on the spur of age, sex and educational background. Microsoft Word and Microsoft Excel were in widespread application to form the tabular and chart icon.

\section{Results}

Table 1. Socio-demographic Shaping of Primary School Kids.

\begin{tabular}{|c|c|c|c|c|}
\hline \multicolumn{5}{|c|}{ Socio-demographic Shaping } \\
\hline \multicolumn{2}{|l|}{ Gender } & \multirow{2}{*}{$\begin{array}{l}\text { Frequency } \\
45\end{array}$} & \multicolumn{2}{|c|}{ Percentage } \\
\hline Boys & & & 60 & \\
\hline Girls & & 30 & 40 & \\
\hline Class standard & Boys & Girls & Boys & Girls \\
\hline Class 1 kids & 9 & 6 & 20 & 20 \\
\hline Class 2 kids & 9 & 6 & 20 & 20 \\
\hline Class 3 kids & 9 & 6 & 20 & 20 \\
\hline Class 4 kids & 9 & 6 & 20 & 20 \\
\hline Class 5 kids & 9 & 6 & 20 & 20 \\
\hline Total & 45 & 30 & 20 & 20 \\
\hline \multicolumn{5}{|l|}{ Papas' Occupation } \\
\hline Government services & \multicolumn{2}{|l|}{43} & \multicolumn{2}{|l|}{57.33} \\
\hline Business & \multicolumn{2}{|l|}{12} & \multicolumn{2}{|l|}{16} \\
\hline Private services & \multicolumn{2}{|l|}{20} & \multicolumn{2}{|l|}{26.67} \\
\hline \multicolumn{5}{|l|}{ Moms' Occupation } \\
\hline Government services & \multicolumn{2}{|l|}{5} & \multicolumn{2}{|l|}{6.67} \\
\hline Private services & \multicolumn{2}{|l|}{10} & \multicolumn{2}{|l|}{13.33} \\
\hline Housewife & \multicolumn{2}{|l|}{60} & \multicolumn{2}{|l|}{80} \\
\hline \multicolumn{5}{|l|}{ Siblings } \\
\hline 1 to 2 & \multicolumn{2}{|l|}{47} & \multicolumn{2}{|l|}{62.67} \\
\hline 3 to 4 & \multicolumn{2}{|l|}{22} & \multicolumn{2}{|l|}{29.33} \\
\hline$>4$ & \multicolumn{2}{|l|}{6} & \multicolumn{2}{|l|}{8} \\
\hline
\end{tabular}

Table 1 is the detector of $60 \%(n=45)$ boys and $40 \%(n=30)$ 
girls shaping a total of 75 primary school going kids in central Bangladesh. There were 20\% $(n=9)$ boys and $20 \%$ $(n=6)$ girls at all the classes from class 1 to class 5 in the concerned three government primary schools campus in Tangail municipality, the central region of developing Bangladesh. 57.33\% $(\mathrm{n}=43), 16 \%(\mathrm{n}=12)$ and $26.67 \%(\mathrm{n}=20)$ kids' papas were government services holders, businessmen and private services holders respectively. Most of the kids moms were housewife $(80 \%, n=60), 13.33 \%(n=10)$ were private services holders and very few were government services holders $(6.67 \%, \mathrm{n}=5)$.

Table 2 is the indicator of most of the kids were in underweight (Quetelet index < 18.5), 80\% ( $\mathrm{n}=12), 73.33 \%$ $(n=11), 86.67 \%(n=13), 80 \%(n=12)$ and $77.33 \%(n=11)$ school kids were underweight at class 1 to class 5 sequentially. There were $20 \%(n=3)$ kids were in normal weight (Quetelet index 18.5 to 25) at classes 1, 2 and 4 while $13.33 \%(n=2)$ and $6.67 \%(n=1)$ were in normal weight at classes 5 and 3 . A tiny bulk of kids $(6.67 \%, n=1)$ were in overweight at classes 2, 3 and 5 making a great tension of having $6.67 \%(\mathrm{n}=1)$ was in obese (Quetelet index $>30)$.

Table 2. Anthropometric Assessment.

\begin{tabular}{|c|c|c|c|c|}
\hline \multicolumn{5}{|c|}{ Outline of Kids' Nutritional Status based on Quetelet Index } \\
\hline \multirow{2}{*}{$\begin{array}{l}\text { Kids } \\
\text { Grouping }\end{array}$} & \multicolumn{4}{|c|}{ Quetelet Index } \\
\hline & $\begin{array}{l}<18.5 \mathrm{n} \\
(\%)\end{array}$ & $\begin{array}{l}18.5 \text { to } 25 \mathrm{n} \\
(\%)\end{array}$ & $\begin{array}{l}25 \text { to } 30 n \\
(\%)\end{array}$ & $\begin{array}{l}>30 n \\
(\%)\end{array}$ \\
\hline Class 1 kids & $12(80)$ & $3(20)$ & $0(0)$ & $0(0)$ \\
\hline Class 2 kids & $11(73.33)$ & $3(20)$ & $1(6.67)$ & $0(0)$ \\
\hline Class 3 kids & $13(86.67)$ & $1(6.67)$ & $1(6.67)$ & $0(0)$ \\
\hline Class 4 kids & $12(80)$ & $3(20)$ & $0(0)$ & $0(0)$ \\
\hline Class 5 kids & $11(73.33)$ & $2(13.33)$ & $1(6.67)$ & $1(6.67)$ \\
\hline
\end{tabular}

Table 3. Hygiene Practice at a Glance.

\begin{tabular}{|c|c|c|c|}
\hline \multicolumn{4}{|c|}{ Kids' Practiced Hygiene Behavior } \\
\hline \multicolumn{4}{|c|}{ Hand Washing Practice } \\
\hline Category & $\begin{array}{l}\text { Wash Hand n } \\
(\%)\end{array}$ & $\begin{array}{l}\text { Don't Wash } \\
\text { Hand n }(\%)\end{array}$ & $\begin{array}{l}\text { Wash Hand } \\
\text { Irregularly n (\%) }\end{array}$ \\
\hline $\begin{array}{l}\text { Before and after } \\
\text { taking meal }\end{array}$ & $75(100)$ & $0(0.00)$ & $0(0.00)$ \\
\hline $\begin{array}{l}\text { After toilet with } \\
\text { soap }\end{array}$ & $75(100)$ & $0(0.00)$ & $0(0.00)$ \\
\hline $\begin{array}{l}\text { Returning home } \\
\text { from outside }\end{array}$ & $74(98.67)$ & $1(1.33)$ & $0(0.00)$ \\
\hline \multicolumn{4}{|c|}{ Brushing frequency } \\
\hline Gender & One n $(\%)$ & Two n $(\%)$ & Three n $(\%)$ \\
\hline Boys & $8(17.78)$ & $35(77.78)$ & $2(4.44)$ \\
\hline Girls & $6(20)$ & $20(66.67)$ & $4(13.33)$ \\
\hline \multicolumn{4}{|c|}{ Sandal Using All the Day } \\
\hline Gender & \multicolumn{2}{|c|}{ Use sandal n (\%) } & $\begin{array}{l}\text { Don't use sandal } \\
\text { n }(\%)\end{array}$ \\
\hline Boys & \multicolumn{2}{|l|}{$44(97.78)$} & $1(2.22)$ \\
\hline Girls & \multicolumn{2}{|l|}{$28(93.33)$} & $2(6.67)$ \\
\hline
\end{tabular}

Table 3 is denotes the basic hygiene practice everyday among the school kids. $100 \%$ respondents washed hand before and after taking meal and after toilet with soap. $98.67 \%(n=74)$ washed hand returning home from outside.
In case of brushing teeth, $77.78 \%(\mathrm{n}=35), 17.78 \%(\mathrm{n}=8)$ and $4.44 \%(n=2)$ boys brushed their teeth two, one and three times a day respectively and on the other hand $66.67 \%$ $(n=20), 20 \%(n=6)$ and $13.33 \%(n=4)$ girls brushed teeth two, one and three times a day respectively. There were $97.78 \%$ $(n=44)$ boys and $93.33 \%(n=28)$ girls used sandal all the day.

\section{Discussion}

The primary school age is the dynamic range of physical, mental social and spiritual growth and development. There is $29.6 \%$ literacy rate in Tangail district, of them $36.1 \%$ is male and $22.4 \%$ female [41]. The proportion of boys is greater than the girl at the primary schools at Tangail, the central part of Bangladesh. The primary school age is generally considered 6 to 13 years in Bangladesh creating a contradictory statement with the UNESCO as UNESCO categorizes 6 to 11 years in frame of primary school age. The study was conducted taking 6 to 11 years kids at boys' and girls' ratio of 3: 2 at each the classes of Town Government Primary School, Darul Ulum Government Primary School and Jahangir Smrity Seberasrom Government Primary School in Tangail municipality as the males' greater literacy rate than the females in Tangail and the UNESCO's age standard. The age of all the study respondents was collected by asking to the kids' guardians and from the school record with the spontaneous helping gesture of the school teachers and hygiene practice was recorded from the kids itself and their guardians. The study showed that $86.67 \%(n=13)$ class 3 kids were in underweight and $80 \%(n=12)$ class 1 and class 4 kids in underweight. The similar findings were found in different studies in different period [42-44]. The study showed that $100 \%$ kids washed hand before and after meal, $77.78 \%(n=35)$ boys and $66.67 \%(n=20)$ girls brushed twice their teeth everyday and only $2.22 \%(n=1)$ boys and $6.67 \%$ $(n=2)$ girls don't use sandal all the day indicating a tremendous hygiene practice among the government primary school kids in central Bangladesh. The hygiene behavior in the study showed the galore improvement of hygiene practice among the school kids in developing Bangladesh [45\&46].

\section{Conclusion}

The study has indicated clearly that the malnutrition is in alarming magnitude among the government primary school kids in central Bangladesh. Screening common health problems and observing hygiene behavior of school kids are mandatory to point out their existing nutritional status. The in time health troubles identification and their solvable measures can form a healthy schooling age to curb their being the burden of society in future. Alleviating different problems and practicing the basic hygiene behavior prior to their school entry and everyday balanced diet continuation and healthy snacks is suggested to make sure their safe childhood to boost safe adulthood. 


\section{References}

[1] Arifa Islam (2012). Tangail District. In Sirajul Islam and Ahmed A. Jamal. Banglapedia: National Encyclopedia of Bangladesh (Second ed.). Asiatic Society of Bangladesh.

[2] UNICEF (1998) Malnutrition: causes, consequences and solution. The state of the world's children.

[3] United Nations International Children's Education Fund (UNICEF) (2009) Water Sanitation and Hygiene Annual Report. P. 5-19.

[4] Rahman, A. and Biswas, S.C. (2009). Nutritional status of under-5 children in Bangladesh. South Asian Journal of Population and Health 2(1), pp. 1-11.

[5] Megabiaw B, and Rahman A. (2013) Prevalence and determinants of chronic malnutrition among under-5 children in Ethiopia. International Journal of Child Health and Nutrition, 2(3), pp. 230-236.

[6] Rahman, A., Chowdhury, S., and Hossain, D. (2009). Acute malnutrition in Bangladeshi children: levels and determinants. Asia-Pacific Journal of Public Health, 21(3), pp. 294-302.

[7] Rahman, A., Chowdhury, S., Karim, A. and Ahmed, S. (2008). Factors associated with nutritional status of children in Bangladesh: A multivariate analysis. Demography India, 37(1), pp. 95-109.

[8] Muller O, Krawinkel (2005) Malnutrition and health in developing countries. CMAJ 173 (3): 279-286.

[9] Rahman, A. and Chowdhury, S. (2007). Determinants of chronic malnutrition among preschool children in Bangladesh, Journal of Biosocial Science, 39(2), pp.161-173.

[10] Kuddus, A. and Rahman, A. (2015). Affect of Urbanization on Health and Nutrition, International Journal of Statistics and Systems, 10(2), pp. 164-174.

[11] Ong SG, Liu J, Wong CM, Lam TH, Tam AY, et al. (1991) Studies on the respiratory health of primary school children in urban communities of Hong Kong. Sci Total Environ 106 (1-2): 121-135.

[12] World Health Organization, Geneva (2008). Water quality interventions to prevent diarrhea: cost and cost-effectiveness.

[13] Hall A, Bobrow E, Brooker S, Jules M, Nokes K, et al. (2001) Anaemia in school children in eight countries in Africa and Asia. Public Health Nutr 4 (30: 749-756.

[14] Pollitt E (1999) Early iron deficiency anaemia and later mental retardation. Am J Clin Nutr 69 (1): 4-5.

[15] Soematri AG, Pollitt E et al. (1985). Iron deficiency anemia and educational achievement. Am J Clin Nutr 42: 1221-28.

[16] Layrisse M, Roche M. (1964) The relationship between anemia and hookworm infection. Am J Hygiene 79: 279301.

[17] Mohammad K, Mohammadreza G, Mohammdi Z (2009) Prevalence of Refractive Errors in Primary School Children [7-15 years] of Qazvin City. European Journal of Science and Research 28: 174-185.

[18] Al-Haddad AM, Hassan HS, Al-Dujaily AA (2006) Distribution of dental caries among primary school children in Al-Mukalla area- Yeamen. Journal of Dent 3: 159-198.
[19] Rahman, A. and Sapkota, M. (2014), Knowledge on vitamin A rich foods among mothers of preschool children in Nepal: impacts on public health and policy concerns, Science Journal of Public Health, 2(4), pp. 316-322.

[20] Sing V, West KP (2004) Vitamin a deficiency and Xeropthalmia among school-aged children in Southeastern Asia. Eur J clin Nutr 58 (10): 1342-1349.

[21] Aswasti S, Clements ACA, Hotez PJ, Hay SI, Tatem AJ, et al. (2006) Intestinal nematode infection and anaemia in developing countries. BMJ 334 (7603): 1065-1066.

[22] Ng'ang'a PM, Valderhaug J (1991) Oral hygiene practices and periodical health in primary school children in Nairobi, Kenya. Acta Odontol Scand 49 (5): 303-309.

[23] Lanzi G, Zambino CA, Termine C, palestra M, Ginevra FO, et al. (2004) prevalence of tic disorders among primary school students in the city of Pavia, Italy. Arch Dis child 89 (1): 45-47.

[24] World Health Organization (2012) Children schools and health; their nutrition and health in Kenya. WHO Global database on child growth and malnutrition (2008). p. 17-20.

[25] Druck B (2010) The dance of climate change and hidden hunger. The Sight band Life magazine 3: 40-59.

[26] Kadiyata S, Gillespie S (2004) Rethinking food aid to fight AIDS. International nutrition foundation for United Nations University. Food and Nutrition Bulletin 25 (3)|: 33-41.

[27] Sally, B., Gormez, A., Rahman, A., and colleagues (2012). Jurisdictional, socioeconomic and gender inequalities in child health and development: Analysis of a national census of 5 year olds in Australia, BMJ Open, 2(5):e001075, pp. 1-15.

[28] United Nations International children's Education Fund (UNICEF) (2000) Nutritional assessment in Nairobi, Kenya, p. 1- 12 .

[29] UNICEF (2006) Food and Nutrition bulletin (supplement) 21 (3): 6-17.

[30] World Food Programme (2013) Overview of Bangladesh.

[31] FAO (2010) Nutrition and consumer protection: Bangladesh summary.

[32] Rahman, A. and Kuddus, A. (2014). Effects of some sociological factors on the outbreak of chickenpox disease, $J P$ Journal of Biostatistics, 11 (1), pp. 37-53.

[33] Kuddus, A. and Rahman, A., Talukder, M.R. and Hoque, A. (2014). A modified SIR model to study on physical behaviour among smallpox infective population in Bangladesh, American Journal of Mathematics and Statistics, 4(5), pp. 231-239.

[34] Weitzmawqn M. (1987) Excessive school absences. Advances Develop Behav Pediatr 8: 151-78.

[35] WHO (2002) Better health for poor children.

[36] Curtis VA, Danquash LO, Aunger RV (2009) Planned, motivated and habitual hygiene behaviour: an eleven country review. Health Educ Res 24 (4): 655-673.

[37] Rahman, A. and Kuddus, A. (2014). A new model to study on physical behaviour among susceptible infective removal population, Far East Journal of Theoretical Statistics, 46(2), pp. 115-135. 
[38] Adhikary M (2013) Nutritional status among primary school children in a Upazila of Bangladesh. Northern International Medical College Journal 4 (2): 265-268.

[39] Rahman, A. and Harding, A. (2013). Prevalence of overweight and obesity epidemic in Australia: some causes and consequences, JP Journal of Biostatistics, 10(1), pp. 31-48.

[40] Rahman, A. and Harding, A. (2010). Some health related issues in Australia and methodologies for estimating small area health related characteristics, Online Working Paper Series: WP-15, NATSEM, University of Canberra, pp. 1-59

[41] D. Shamsul Haque Mia (March 1999). Education in Tangail. Tangail Forum. Pp. 26-27

[42] Gupta RK, Bhat A, Khajuria RK, Bhat AM (1997) Health status of primary school children in Jammu. Indian Journal of
Preventive and social Medicine 28 (3-4): 90-94.

[43] Sharif ZM, Bond N (2000) Nutritional status of primary school children from low income households in kuala Lumpur. Malays J Nutr 6 (1): 17-32.

[44] Hasan MM, Hoque MA, Hossain MA, Mollah AH, et al. (2013) Nutritional status among primary school children of Mymensingh. Mymensingh Med J 22 (2): 267-274.

[45] Allen AH, Gillespie SR (2001) What Works. A review of the Efficacy and Effectiveness of Nutritional Interventions. United Nations Administrative Committee on Coordination sub-committee on nutrition. Asian Development bank. Page 8-16.

[46] Sharmin AS (2008) Hygiene promotes teach safe sanitation practices in Bangladesh. 